\title{
O s dois Brasis: quem são, onde estão e como vivem os pobres brasileiros
}

\author{
An a Lydia SaWAya, Gisela M. B. SOlymos, \\ TElma Maria de MeneZes Toledo FlorênCIO \\ E PAULA ANDREA MARTINS
}

\section{Q uem são e onde estão os pobres}

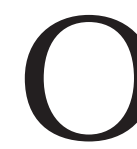

BRASIL É O TERCEIRO país com maior desigualdade de renda no mundo, estando atrás apenas de M alavi e África do Sul (Barrose H enriques, 2001). $\mathrm{H}$ á dois Brasis, no imenso território nacional. U m contingente significativo da população está à margem, clandestina e excluída da sociedade brasileira oficial. M ilhões de pessoas e grupos humanos não têm certidão de nascimento, de batismo ou casamento, não têm endereço, não pagam conta de água, luz ou telefone, não possuem carteira de trabalho, não pagam impostos, não têm conta no banco, não sabem ler ou não entendem o que lêem, e não conseguirão entrar no mercado de trabalho oficial, cada vez mais qualificado. É a população com maior mobilidade geográfica; a primeira a ficar desempregada em momentos de crise e a que mais sofre 0 impacto da instabilidade econômica. Tem a mais alta freqüência de intercorrências médicas (da infância à velhice), uma expectativa de vida quase vinte anos menor do que a população mais rica, e uma taxa de mortalidade três vezes mais alta (Duncan e cols., 1995). É um outro Brasil, pouco conhecido e cuja realidade fica obscurecida nos estudos que analisam apenas médias nacionais. É uma população tão pouco observada, que as três perguntas fundamentais: quem e quantos são os pobres?, onde vivem? e quais os seus principais problemas? permanecem ainda sem resposta adequada. Segundo documento recente da FAO (2001), as respostas a essas perguntas são condição obrigatória para que qualquer intervenção seja efetiva.

N o Brasil, não existe até hoje uma política global, coordenada e efetiva de combate à pobreza (Banco M undial, 1996). A pesar disso, o país, segundo vários estudiosos, gasta uma quantidade grande de recursos em projetos sociais, mal focados eineficientes (N EPP, 1994; Banco M undial, 1996; Banco M undial, 2001). Portanto, para promover uma ação global, efetiva e duradoura do combate à pobreza no Brasil, é necessário que se observe e se conheça detal hadamente a situação de vida, saúde e nutrição do "Brasil pobre". Só para dar um exemplo da importância desse conhecimento, o novo programa do governo federal prevê o com- 
bate à pobreza e à fome tendo como objetivo primordial, entre outros, a distribuição de alimentos, como organismos internacionais (FAO, 2001), em linha com estudos nacionais, mostram que podem ser mais efetivos, a redução do analfabetismo materno (G uimarães e cols., 1999 e Kac, 1999) e a ampliação dos serviços de saúde - especialmente aqueles que rompem o isolamento característico dos mais pobres (Szwarcwald e cols., 2002) realizando visitas domiciliares, como 0 Programa de Saúde da Família e os agentes comunitários de saúde.

$\mathrm{H}$ á dois grupos de pobres no Brasil, com condições de vida relativamente distintas, embora haja grande mobilidade entre eles: o pobre rural eo urbano, morador em favelas. 0 primeiro grupo vem diminuindo fortemente nas últimas décadas devido ao êxodo rural enquanto o segundo só tem aumentado. $\mathrm{H}$ oje, $82 \%$ da população brasileira vive na zona urbana ( 0 pas, 1998), tanto nas grandes cidades como nas pequenas cidades do interior. As condições de vida dos pobres, seja nas cidades grandes, seja nas pequenas, são semelhantes no que se refere à atividade econômica, alimentação etc. U m exemplo do crescimento da população pobre em zona urbana é o município de São Paulo, cuja população moradora em favelas era desprezível antes da década de 1970 (M arques e cols., 2003) e hoje compreende cerca de 15 a 20\% da população do município: ou seja, 1,2 a dois milhões de pessoas (dependendo do método de cálculo) moram em favelas (M arques e cols., 2003; Sehab, 1994).

Estudos que diferenciam a população rural da população urbana pobre mostram que a situação de saúde, nutricional e de pobreza é pior no campo e este é o motivo para tão grande êxodo rural, entre outros fatores ( O pas, 1998). Estimase que cerca de $10 \%$ dos pré-escolares tenham retardo do crescimento no Brasil (Benfam, 1997), enquanto no N ordeste rural a prevalência de nanismo em crianças de até dez anos é de 39,8\% (Ferreira e cols., 1996). Esta alta prevalência de desnutrição na zona rural confunde, porém, o tamanho do problema, pois em termos absolutos, é maior o número de crianças desnutridas que se encontram nos bolsões de pobreza e favelas das zonas urbanas, uma vez que a maioria dos brasileiros vive hoje em zona urbana.

A pobreza urbana e a rural difere bastante entre si. Essas diferenças precisam ser bem conhecidas para que intervenções adequadas possam ser efetivas e atuar nos problemas mais determinantes para o quadro de pobreza. No N ordeste rural, por exemplo, acesso a estradas para escoamento da produção agrícola, falta de crédito rural, secas que provocam fome sazonal, falta de acesso à água, pouca cobertura dos serviços de saúde etc., são fatores determinantes para a condição de vida e pobreza. J á a pobreza e a desnutrição da zona urbana têm outros fatores mais determinantes, como baixa escolaridade materna, gravidez na adolescência, desemprego, violência e isolamento social, drogadição, condições de moradia e saneamento inadequadas, maus hábitos alimentares influenciados pela propaganda das indústrias de alimentos (consumo diário de refrigerantes, salgadinhos e biscoitos, por exemplo) etc. 
Este artigo procurará mostrar alguns dados sobre as condições nutricionais e de pobreza de duas populações moradoras em favelas, nos municípios de M aceió e São Paulo. O s resultados apresentados revelam que no Brasil atual, a associação entre pobreza e estado nutricional (incluindo desnutrição energético-protéica e obesidade) é complexa e ainda pouco conhecida.

\section{Fome, desnutrição, obesidade e insegurança alimentar}

Antes de descrever os dados sobre avaliação do estado nutricional em populações pobres, é necessário definir os termos utilizados:

FOME = diminuição da quantidade de alimento consumido por falta ou dificuldade de acesso.

N os países onde a fome tem alta prevalência, como na África ao sul do Saara, esta acontece, em geral, devido à seca e à guerra. Só neste caso recomendam-se

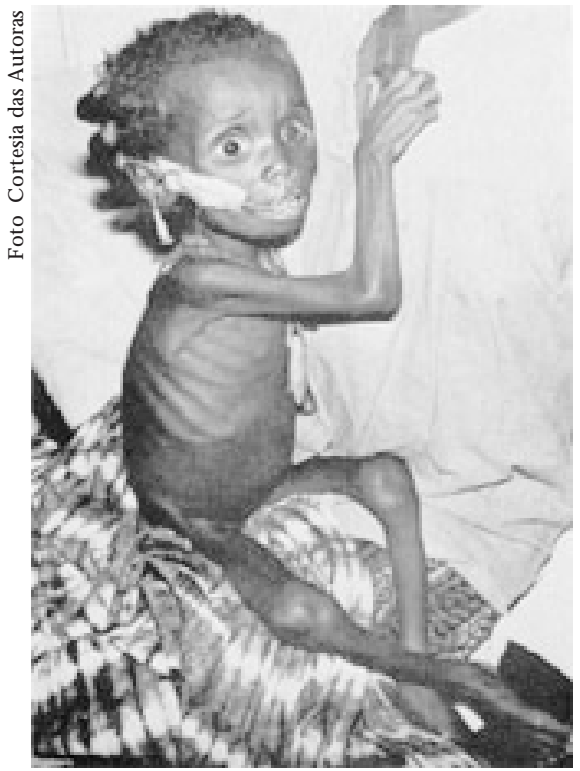

Criança africana com fome aguda grave. medidas emergenciais de distribuição de alimentos. A fome está associada a taxas muito altas de mortalidade. Acontece em baixa prevalência no Brasil, em geral no Nordeste rural, quando há seca. M as é muito raro que pessoas morram de fome no Brasil. A melhor forma de se medir a presença de fome em uma população, seja de crianças como de adultos, é a avaliação das reservas energéticas do indivíduos, representadas pela quantidade de gordura corporal, a partir da aferição da relação peso/ estatura ou do Í ndice de M assa Corporal (peso expresso em $\mathrm{kg}$ dividido pelo quadrado da altura expressa em metros). D e acordo com o último levantamento populacional realizado no Brasil, a PN D S de 1996 (Benfam, 1997), o percentual de adultos e crianças com déficit peso/ estatura, era entre 3 e 4\%, taxa semelhante à de países desenvolvidos. $\mathrm{M}$ esmo em áreas rurais da região $\mathrm{N}$ ordeste, essa taxa era menor do que $5 \%$

DESN UTRIÇÃO ENERGÉTICO-PROTÉICA = diminuição da quantidade de alimentos + qualidade inadequada (falta proteínas de boa qualidade, vitaminas e minerais) + aumento da freqüência, duração e intensidade de infecções.

Estes três fatores estão associados entre si formando um ciclo vicioso perverso, cada qual aumentando a influência negativa do outro. A insuficiência alimentar (quantidade e qualidade) prejudica o sistema imunológico levando a uma menor resistência às infecções; e o aumento da duração, intensidade e freqüência das infecções prejudica a al imentação e absorção dos alimentos. Este ciclo vicioso 
é tão forte que apenas a distribuição de alimentos ou o tratamento isolado das patologias associadas (em unidades de saúde), não são efetivos para a recuperação do estado nutricional e a manutenção da saúde. A desnutrição é mais nociva em crianças e gestantes, pois o organismo, além de precisar se alimentar para a manutenção da vida necessita ainda crescer ou sintetizar tecidos corporais. Esta, em geral, é uma condição crônica, decorrente da pobreza. É o problema brasileiro típico. A desnutrição causa baixa estatura e baixo peso associados a um aumento na morbidade (doenças) e mortalidade. No Brasil, a prevalência de baixa estatura é duas vezes mais alta do que baixo peso. 0 s fatores em preto são aqueles geralmente esquecidos nas políticas e programas brasileiros atuais. 0 que torna a recuperação nutricional pouco efetiva. A qualidade protéica da dieta é fundamental para a recuperação em estatura (Solymos e cols., 1997) e para a saúde do adulto (Sichieri e cols., 2000; Florêncio e cols., 2001). As causas mais comuns da desnutrição infantil, em nosso meio, são: baixa escolaridade materna, falta de cuidados adequados no prénatal e desmame inadequado (precoce ou associado a alimentação complementar inadequada). Esses fatores estão associados à falta de conhecimentos básicos de higiene, condições insalubres de moradia, falta de cuidados de saúde, falta

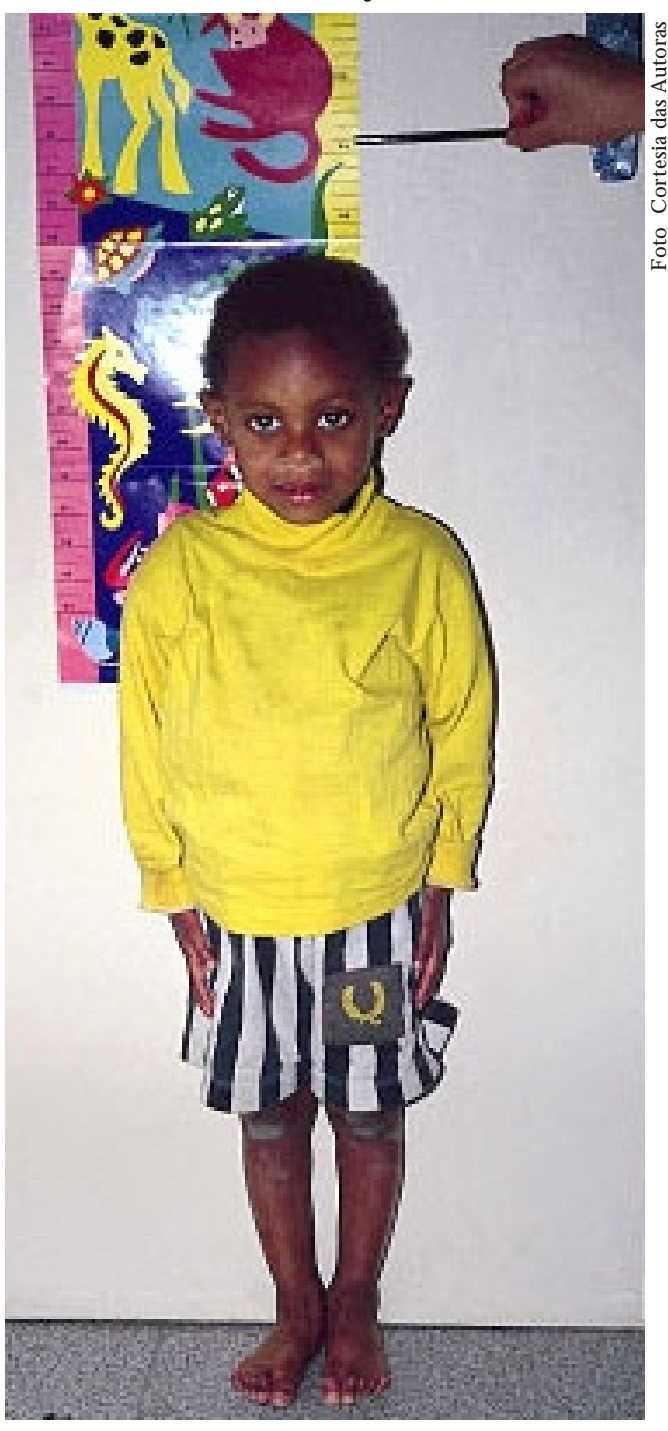

Criança com déficit de estatura para idade. de diversificação e adequação da dieta, além de desemprego ou subemprego, alimentação deficiente e ganho de peso na gestação insuficiente.

$O B E S I D A D E=$ ganho de gordura corporal e peso em relação à estatura.

A obesidade ocorre devido a um balanço energético positivo, ou seja, aumento na energia estocada: EN ERGIA ESTOCADA =ENERGIA IN GERIDA ENERGIA GASTA

$N$ as últimas décadas passou-se a compreender a obesidade não mais como uma relação direta entre energia ingerida $\rightarrow$ energia etocada. Verificou-se que um outro fator, a energia gasta, interferia grandemente nesta relação; sendo con- 
siderada por muitos autores até mais importante do que a energia ingerida para a promoção da obesidade. Este fator é ainda pouco conhecido fora do âmbito científico. A energia gasta ou gasto energético tem ganhado importância na medida em que crescem o número de estudos mostrando que a obesidade tem ocorrido em populações pobres que vivem em zona urbana, nos países em desenvolvimento; inclusive co-existindo com a desnutrição (Sawaya e cols., 1995; Doak e cols., 2000). Além disso, a relação entre energia ingerida e energia estocada torna-se mais complexa quando se considera que no componente energia ingerida são importantes não só a quantidade de energia ingerida mas o tipo (gorduras e/ ou açúcares refinados). M uitos autores sugerem que o tipo de energi a ingerida pode ser mais importante para que o corpo estoque gordura do que a quantidade de energia em si (Sawaya e cols., 2003). A energi a gasta depende da atividade física e/ ou da regulação dos mecanismos fisiológicos de conservação de energia e depósito de gordura.

IN SE GU RAN ÇA ALIM ENTAR = impossibilidade de acesso seguro e suficiente a alimentos e nutrientes para o crescimento e desenvolvimento normais, e vida ativa e saudável.

Pode ser causada por falta de alimentos, poder de compra insuficiente ou distribuição inadequada de alimentos em âmbito domiciliar. A insegurança alimentar pode ser crônica, sazonal ou transitória. 0 conceito de insegurança alimentar ainda está em construção. Ele parte de avaliações de caráter econômico (renda familiar e linha de pobreza, renda familiar/ preço da cesta básica, rendaper capita/ quantidades de calorias diárias disponíveis no domicílio). $\mathrm{H}$ á vários modos de cál culo, com diferenças grandes entre eles. Por exemplo, 0 modo de calcular do Banco M undial é a renda fa-

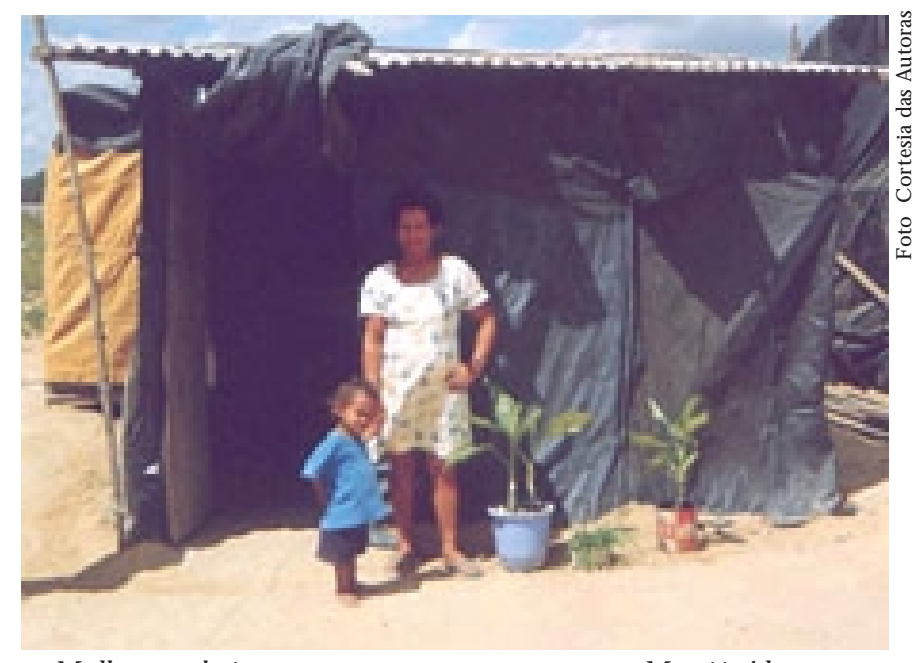

Mulher com baixa estatura, em um acampamento Maceió, A lagoas. miliar dividida pelo gasto domiciliar com alimentos; e o da FAO infere o consumo alimentar mínimo de $1900 \mathrm{kcal}$ (depende da idade e sexo) por pessoa em relação à disponibilidade de al imentos (FAO , 2001). A FAO criou o termo "subnutrição" a partir desses cálculos. É importante destacar que essas são avaliações indiretas e por isso imprecisas, e apenas inferem o que ocorreria, teoricamente, nos indivíduos que supostamente sofrem de insegurança alimentar. É uma inferência, não uma medida direta a afirmação de que a insegurança alimentar leva obrigatoria- 
mente à magreza (e portanto fome). Para comprovar se essa afirmação é verdadeira em qualquer situação, é necessário realizar a avaliação do estado nutricional como descrito anteriormente: peso, estatura e quantidade de gordura estocada; ou seja, avaliar o que acontece efetivamente no organismo humano a partir dos alimentos ingeridos. 0 presente artigo procurará mostrar que realizar políticas baseando-se apenas no conceito de insegurança alimentar, pode incorrer em grandes erros, em países em que a prevalência de obesidade, cardiopatias e diabetes está aumentando, como no Brasil, especialmente entre os pobres.

\section{Situação socioeconômica e nutricional de famílias moradoras em favelas de São Paulo}

\section{A desnutrição está associada a condições insalubres de moradia}

Censos antropométricos e socioeconômicos foram realizados diretamente em 22 favelas de São Paulo em 1990-1991 (Sawaya, 1997). N ão se observou diferenças nas condições socioeconômicas entre elas. A maioria dos adultos eram migrantes (88\%) e $70 \%$ deles vinham do $\mathrm{N}$ ordeste. M uitas crianças também eram migrantes $(26,5 \%)$ sendo que destas $79 \%$ eram nordestinas. N oventa por cento da população estudada estava abaixo da linha de pobreza, ou seja, ganhava menos que um dólar/ dia. O s dados de analfabetismo e escolaridade mostraram que $20 \%$ dos homens e $23 \%$ das mulheres eram analfabetos e $11 \%$ dos homens e $15 \%$ das mulheres nunca haviam freqüentado a escola. 0 analfabetismo estava presente em uma porcentagem alta de crianças acima de dez anos (12\%).

A maioria dos barracos era de madeira e possuía condições sanitárias inadequadas (Tabela 1). U ma observação interessante foi a de que as famílias, já no início da década de 1990, não eram numerosas. A pesar das condições de renda e de moradia serem tão precárias e da prevalência de desnutrição ser alta - das famílias estudadas 44\% (Sawaya, 1997) possuíam pelo menos um membro com desnutrição, de acordo com os critérios de Gomez (Gomez e cols., 1956) e Wartelow (1976) - nem todas as famílias sofriam de desnutrição. Encontrou-se também $15 \%$ de famílias com pelo menos um membro obeso.

Análises de regressão logística múltipla foram realizadas para identificar quais seriam os fatores que mais se associavam à presença de desnutrição crônica (baixa estatura) na família (Tabela 2). No modelo completo, a variável mais importante foi falta de piso em pelo menos um cômodo da casa, enquanto morar em barraco de madeira mostrou uma significância estatística marginal. Em uma segunda análise, após a eliminação das variáveis menos significantes, os fatores mais importantes para explicar a presença de desnutrição na casa foram falta de piso $(b=0,739, O R=2,1, p=0,027)$ e ausência de torneira no domicílio $(b=0,489, O R=1,6, p=0,042)$. A chance de uma criança ou adolescente ( 0 -18 anos) possuir baixa estatura foi duas vezes mais alta quando não havia piso em todos os cômodos e aumentava em $60 \%$ quando não havia abastecimento de água encanada em casa. 
Tabela 1 - Condições socioeconômicas das famílias moradoras de 22 favelas do município de São Paulo.

\begin{tabular}{|ll|}
\hline POPULAÇÃO & 535 \\
Famílias, $\mathrm{n}$ & 2411 \\
Pessoas, $\mathrm{n}$ & 4,55 \\
\hline Pessoas por família & \\
\hline RENDA & 0,54 \\
\hline Renda média per capita (dólares/dia) & \\
\hline CONDIÇÕES DO DOMICílıIO & 2,08 \\
Número de cômodos & 26 \\
Tipo de construção & 74 \\
$\quad$ alvenaria, \% & 4 \\
$\quad$ madeira, \% & 11 \\
Ausência de fornestimento no piso, \% & 64 \\
Fornecimento de água freqüentemente interrompido, \% & 13 \\
Ausência de banheiro, \% & 20 \\
Esgoto a céu aberto, \% & \\
\hline
\end{tabular}

Tabela 2 - M odelo de regressão logística múltipla usado para estimar o risco de baixa estatura em crianças, de ambos os sexos, de zero a dezoito anos de idade, moradoras em 22 favelas do município de São Paulo.

\begin{tabular}{|l|c|c|c|c|c|}
\hline & $\begin{array}{c}\text { Coeficiente } \\
(\mathbf{B})\end{array}$ & $\begin{array}{c}\text { Erro } \\
\text { padrão }\end{array}$ & $\mathbf{p}$ & $\begin{array}{c}\text { Odds } \\
\text { ratio }\end{array}$ & IC 95\% \\
\hline Constante & $-2,324$ & 0,773 & 0,003 & & \\
\hline $\begin{array}{l}\text { Interrupção no } \\
\text { fornecimento de água }\end{array}$ & $-0,023$ & 0,166 & 0,890 & 0,977 & $(0,706 ; 1,354)$ \\
\hline $\begin{array}{l}\text { Tipo de construção - } \\
\text { madeira }\end{array}$ & $-0,404$ & 0,212 & 0,057 & 0,668 & $(0,441 ; 1,012)$ \\
\hline $\begin{array}{l}\text { Número de cômodos } \\
\text { por domicílio }\end{array}$ & $-0,023$ & 0,045 & 0,618 & 0,978 & $(0,895 ; 1,068)$ \\
\hline Piso sem revestimento & 0,693 & 0,345 & 0,045 & 1,999 & $(1,017 ; 3,930)$ \\
\hline Esgoto a céu aberto & 0,300 & 0,204 & 0,141 & 1,350 & $(0,905 ; 2,012)$ \\
\hline Ausência de banheiro & 0,068 & 0,278 & 0,806 & 1,071 & $(0,621 ; 1,845)$ \\
\hline $\begin{array}{l}\text { Ausência de água } \\
\text { encanada }\end{array}$ & 0,445 & 0,273 & 0,103 & 1,561 & $(0,915 ; 2,663)$ \\
\hline Renda per capita & $-0,065$ & 0,130 & 0,618 & 0,937 & $(0,726 ; 1,209)$ \\
\hline Escolaridade materna & 0,122 & 0,178 & 0,491 & 1,130 & $(0.798 ; 1,602)$ \\
\hline
\end{tabular}

Esses dados demonstram a importância da melhoria das condições de saneamento básico para se evitar a desnutrição. 


\section{C oexistência entre desnutrição e obesidade}

O estado nutricional da população total pode ser observado nas Figuras 1 e 2. A avaliação do estado nutricional de crianças, adolescentes e adultos mostrou, sobretudo nestes dois últimos grupos, a presença de desnutrição e de obesidade. $\mathrm{U} \mathrm{m}$ dado intrigante foi ter encontrado meninas adolescentes com baixa estatura (desnutrição pregressa) e ao mesmo tempo obesas, sendo que a prevalência deste grupo foi quase duas vezes mais alta do que o grupo de meninas obesas com estatura normal (Figura 1). U m outro dado que chamou a atenção foi ter encontrado a presença simultânea de desnutrição e obesidade na mesma família (13\% das famílias tinham pelo menos um membro desnutrido e um membro obeso) (Sawaya, 1997). Esses dados, por si só já mostram a importância de se classificar o estado nutricional para programas de combate à desnutrição, sendo 0 corte por renda impreciso para populações pobres que vivem em zonas urbanas.

Figura 1 - Estado nutricional de crianças e adolescentes moradores de 22 favelas no município de São Paulo.

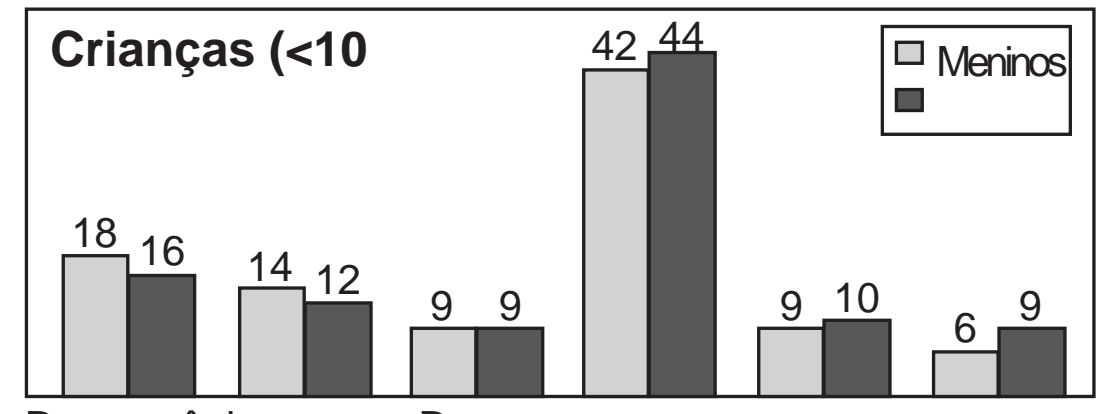

Desn. crônica

Desn. pregressa

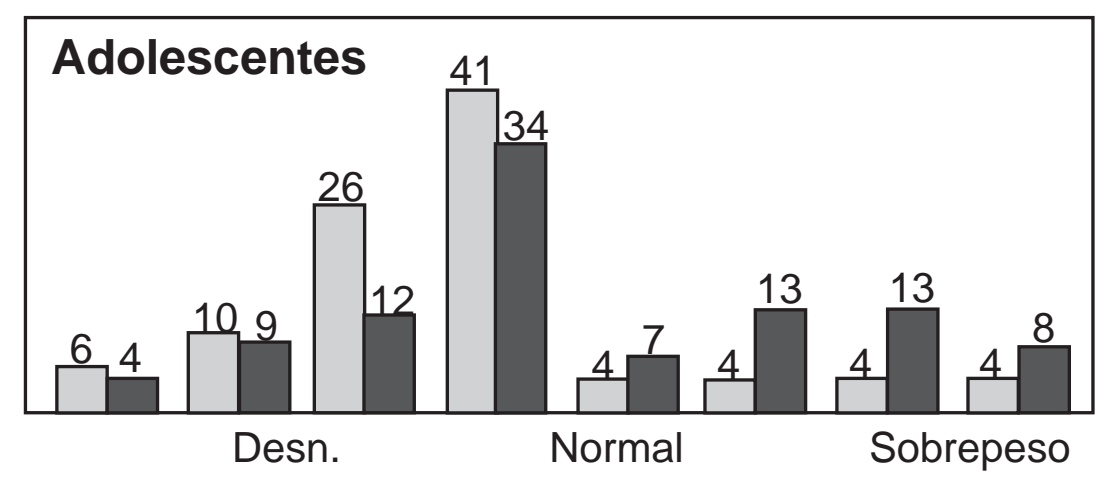

Desn. atual Desn, Sobrepeso +

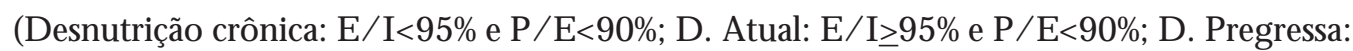
E/ I <95\%e P/ E entre 90 e 100\% N ormal: E/ I $\geq 95 \%$ e P/ E entre 90 e100\%; Sobrepeso: E/ I $\geq 95 \%$ e P/ E $\geq 110 \%$ e <120; O besidade: E / I $\geq 95 \%$ e P/ E $\geq 120 \%$; Sobrepeso +Baixa Estatura: E/ I <95\% e P/ E $\geq 110 \%$ e <120; O besidade+Baixa Estatura: E/ I <95\% e P/ E $\geq 120 \%$ ). 
Chamou ainda bastante atenção o fato de que, entre os adultos, a prevalência de indivíduos com sobrepeso e obesidade ser maior do que a de indivíduos desnutridos (Figura 2). Este estudo, infelizmente, não averiguou o consumo alimentar para saber se os indivíduos obesos consumiam alimentos além de suas necessidades energéticas.

Figura 2 - Estado nutricional de adultos moradores em 22 favelas do município de São Paulo.

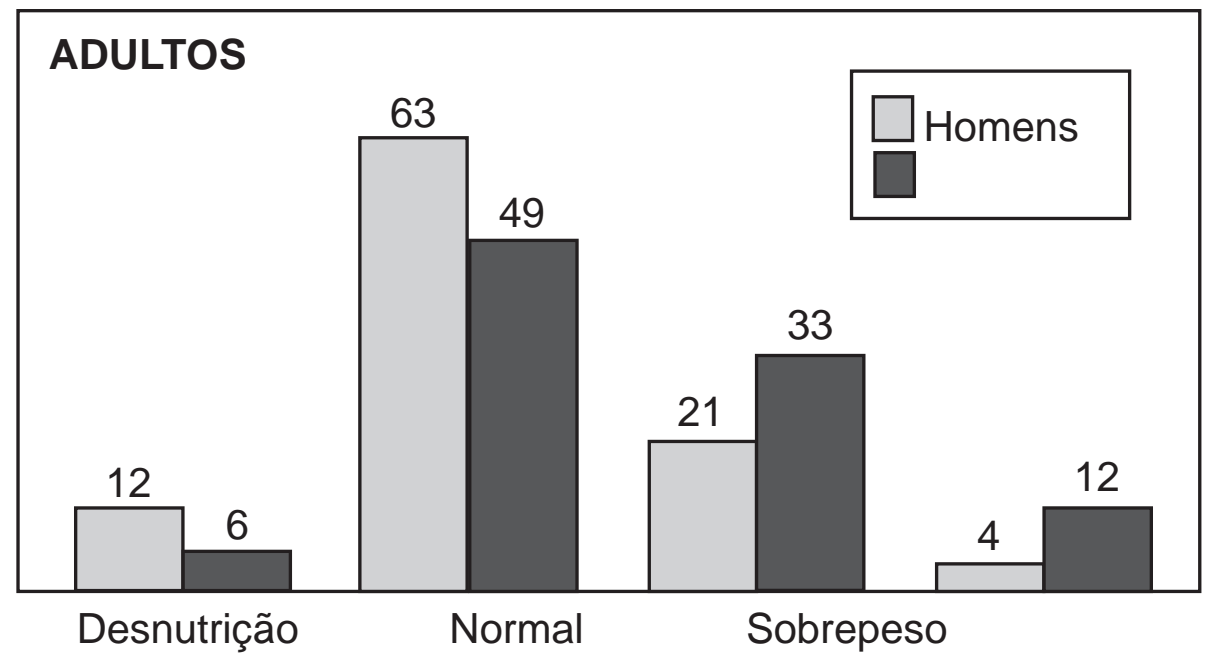

(D esnutrição: I M C $\leq 20$; N ormal: IM C $>20$ e $<25$; Sobrepeso: IM C $\geq 25$ e $<30$; O besidade: IMC $\geq 30$ ).

A presença de alguns indivíduos obesos e outros desnutridos em uma mesma família, assim como de meninas adolescentes com baixa estatura (decorrente de desnutrição na infância), e obesidade, são fatos cuja coexistência parece incompatível. Se há uma prevalência alta de desnutrição, ocorre claramente uma insuficiência alimentar decorrente da pobreza e da baixa renda, com dificuldade de acesso aos alimentos devido a esta última. Como pode então ocorrer obesidade?

A única explicação plausível poderia estar nos inúmeros mecanismos que o corpo dispõe para controlar o gasto energético. 0 ser humano, frente a episódios freqüentes de fome, pode lançar mão de uma série de mecanismos fisiológicos para poupar energia e acumular gordura em detrimento do crescimento em estatura. A gordura éo grande armazém energético do corpo e garantia para sobrevivência em tempos de fome. Estudos sobre a Fome H olandesa durante a Segunda Guerra M undial mostraram que meninos que haviam sofrido fome na primeira fase de gestação desenvolveram uma capacidade maior de armazenar gordura e mostraram uma incidência maior de obesidade aos dezenove anos ( Ravelli e cols, 1976). Vários relatos na literatura confirmaram esses achados. Ganho de peso 
excessivo, sobretudo de obesidade central (acúmulo de gordura na região do abdômen) que é o tipo de obesidade mais associado a doenças e morte prematura, foi observado em crianças de países desenvolvidos que sofreram desnutrição intra-uterina (causas não relacionadas à pobreza) (Law e cols., 1992; Kuh e cols, 2002; L oos e cols, 2002). Essas crianças, quando se tornaram adultas, apresentaram alta prevalência de hipertensão e tiveram mais mortes por cardiopatias e diabetes (Roseboom e cols., 1999).

\section{Situação socioeconômica e nutricional de famílias moradoras em favelas de M aceió \\ D esnutrição, obesidade e consumo de alimentos}

Além dos estudos realizados em favelas de São Paulo, investigamos também uma população extremamente pobre moradora em um acampamento de "sem-teto" no município de M aceió, em 1999 (Florêncio e cols., 2001). A Tabela 3 descreve condições socioeconômicas e nutricionais ainda piores do que as de São Paulo. A quase totalidade da população morava em casas de plástico sem qualquer saneamento básico ou abastecimento de água. $\mathrm{N}$ a sua grande maioria, era desempregada e vivia de bicos esporádicos, além de ser analfabeta. Toda a população encontrava-se abaixo da linha de pobreza (Tabela 3).

Essas condições explicam as altas prevalências de desnutrição moderada/ grave nas crianças ( $21 \%$, -2 escore Z) e adultos (19,5\%, Í ndice de M assa Corporal $<20 \mathrm{~kg} / \mathrm{m}^{2}$, calculado daTabela 4). Por outro lado, impressiona novamente a paradoxal coexistência, nos adultos, de desnutrição e sobrepeso/ obesidade. $\mathrm{N}$ as mulheres, as prevalências de desnutrição e obesidade mostraram-se mais altas que nos homens (Tabela 4).

Q uando analisamos a ingestão alimentar dos adultos, verificou-se que estes possuíam uma dieta muito monótona, pobre e com pouca diversidade (Tabela 5). 0 consumo energético (ajustado para estatura) mostrou-se bem abaixo do requerimento energético, mesmo para os indivíduos obesos (Tabela 6 ). U m dado que chamou muito a atenção foi o consumo energético semelhante nas mulheres baixas, obesas ou desnutridas.

O consumo de alimentos parece, portanto, não ser o diferencial mais importante entre as mulheres obesas e aquelas com desnutrição. Q uais outros fatores estariam envolvidos? U m fator que seguramente pode ter contribuído para a o besidade foi a redução da atividade física ocorrida pela mudança do campo para a cidade.

E sses dados revelam também quão complexa é a relação entre consumo de alimentos e estado nutricional. Vários podem ser os mecanismos de economia de energia que o corpo lança mão em situações de dificuldade. 
Tabela 3 - Condições socioeconômicas em um acampamento de "Sem-Teto" em M aceió, Alagoas, 1999.

\begin{tabular}{|c|c|c|c|}
\hline \multicolumn{4}{|l|}{ População } \\
\hline \multicolumn{3}{|l|}{ Número de famílias } & 315 \\
\hline \multicolumn{3}{|l|}{ Número de pessoas } & 1247 \\
\hline \multicolumn{3}{|c|}{ Número médio de pessoas por barraco } & 4 \\
\hline \multicolumn{4}{|l|}{ Renda } \\
\hline \multicolumn{3}{|c|}{ Renda familiar mensal (em dólares) } & $40,32^{*}$ \\
\hline \multicolumn{3}{|c|}{ Renda per capita (dólares/dia) } & $0,32^{*}$ \\
\hline \multicolumn{4}{|c|}{ Escolaridade ( $\geq 7$ anos de idade) } \\
\hline \multirow{3}{*}{\multicolumn{3}{|c|}{$\begin{array}{l}\text { Sabem ler } \\
\text { Sabem escrever } \\
\text { Analfabetos }\end{array}$}} & $37,3 \%$ \\
\hline & & & $36,7 \%$ \\
\hline & & & $63,3 \%$ \\
\hline \multicolumn{4}{|l|}{ Ocupação } \\
\hline \multirow{2}{*}{\multicolumn{3}{|c|}{$\begin{array}{l}\text { Desempregados } \\
\text { Trabalhadores contratados }\end{array}$}} & $81,6 \%$ \\
\hline & & & $3,6 \%$ \\
\hline \multicolumn{4}{|l|}{ Condições de moradia } \\
\hline \multirow{4}{*}{\multicolumn{3}{|c|}{$\begin{array}{l}\text { Casas feitas de plástico } \\
\text { Sem revestimento de piso } \\
\text { Sem geladeira } \\
\text { Domicílios de um cômodo }\end{array}$}} & $81,0 \%$ \\
\hline & & & $91,0 \%$ \\
\hline & & & $80,6 \%$ \\
\hline & & & $89,0 \%$ \\
\hline \multicolumn{4}{|l|}{ Saneamento } \\
\hline \multirow{3}{*}{\multicolumn{3}{|c|}{$\begin{array}{l}\text { Casas sem fornecimento de água } \\
\text { Casas sem banheiro } \\
\text { Casas sem água tratada para beber }\end{array}$}} & $97,0 \%$ \\
\hline & & & $95,0 \%$ \\
\hline & & & $78,0 \%$ \\
\hline \multirow{2}{*}{\multicolumn{4}{|c|}{$\begin{array}{l}\text { =onte: Florêncio e cols., } 2001 . \\
\text { * Taxa de câmbio em 30/ 9/ 1999: U S\$ 1 =R\$1,87 }\end{array}$}} \\
\hline \multicolumn{2}{|c|}{ Taxa de câmbio em 30/ 9/ 1999: U S\$1 = R \$1,87 } & & \\
\hline \multicolumn{4}{|c|}{$\begin{array}{l}\text { Tabela } 4 \text { - Classificação nutricional segundo Í ndice de M assa Corpórea (I M C), } \\
\text { de adultos moradores de acampamento de "Sem-Teto" em M aceió, Alagoas, } 1999 .\end{array}$} \\
\hline \multirow{2}{*}{ IMC } & \multicolumn{2}{|c|}{ SEXO } & \multirow{2}{*}{ TOTAL } \\
\hline & Masculino & Feminino & \\
\hline & $\mathbf{N}(\%)$ & $\mathbf{N}(\%)$ & $\mathbf{N}(\%)$ \\
\hline Desnutrição $(<20$ kg/m²) & $42(16,9)$ & $62(22,1)$ & $104(19,5)$ \\
\hline Normal $\left(\geq 20<25 \mathrm{~kg} / \mathrm{m}^{2}\right)$ & $166(66,1)$ & $229(45,9)$ & $295(55,5)$ \\
\hline Sobrepeso $\left(\geq 25<30 \mathrm{~kg} / \mathrm{m}^{2}\right)$ & $40(15,9)$ & $65(23,1)$ & $105(19,7)$ \\
\hline Obesidade $\left(>30 \mathrm{~kg} / \mathrm{m}^{2}\right)$ & $03(1,2)$ & $25(8,9)$ & $28(5,3)$ \\
\hline Total & $251(47,2)$ & $281(52,8)$ & $532(100,0)$ \\
\hline
\end{tabular}

Fonte: Florêncio e cols., 2001. 
Tabela 5 - Preparações consumidas nas principais refeições por homens e mulheres moradores em acampamento de "Sem-Teto" em M aceió, Alagoas.

\begin{tabular}{|c|c|l|}
\hline Refeições & $\begin{array}{c}\text { No de } \\
\text { preparações } \\
\text { referidas }\end{array}$ & \multicolumn{1}{|c|}{$\begin{array}{c}\text { Preparações citadas (por ordem } \\
\text { de freqüência) }\end{array}$} \\
\hline DESJEJUM & 13 & $\begin{array}{l}\text { Café c/ açúcar, pão, cuscuz de milho, ovo frito, } \\
\text { bolacha cream cracker, frango, leite em pó, } \\
\text { macaxeira, carne, biscoito doce, suco de frutas, } \\
\text { salame, mortadela. }\end{array}$ \\
\hline LANCHE & 9 & $\begin{array}{l}\text { Pão c/ margarina, bolacha cream cracker, } \\
\text { refrigerante, suco de frutas, biscoito doce, café c/ } \\
\text { açúcar, balas, banana. }\end{array}$ \\
\hline ALMOÇO & 12 & $\begin{array}{l}\text { Feijão, arroz, macarrão, frango, farinha, carne, } \\
\text { peixe, ovo frito, suco de frutas, café c/ açúcar, } \\
\text { charque, fígado. }\end{array}$ \\
\hline JANTAR & 21 & $\begin{array}{l}\text { Café c/ açúcar, cuscuz, arroz, pão c/ margarina, } \\
\text { feijão, frango, ovo frito, carne, macarrão, peixe, } \\
\text { farinha, charque, leite, macaxeira, biscoito doce, } \\
\text { salame, batata doce, sardinha, inhame. }\end{array}$ \\
\hline CEIA & 3 & Café, bolacha cream cracker, leite. \\
\hline
\end{tabular}

Fonte: Florêncio e cols., 2003.

Tabela 6. Adequação do consumo de energia da população adulta moradora em acampamento de "Sem-Teto" em M aceió, Alagoas, segundo sexo e características antropométricas.

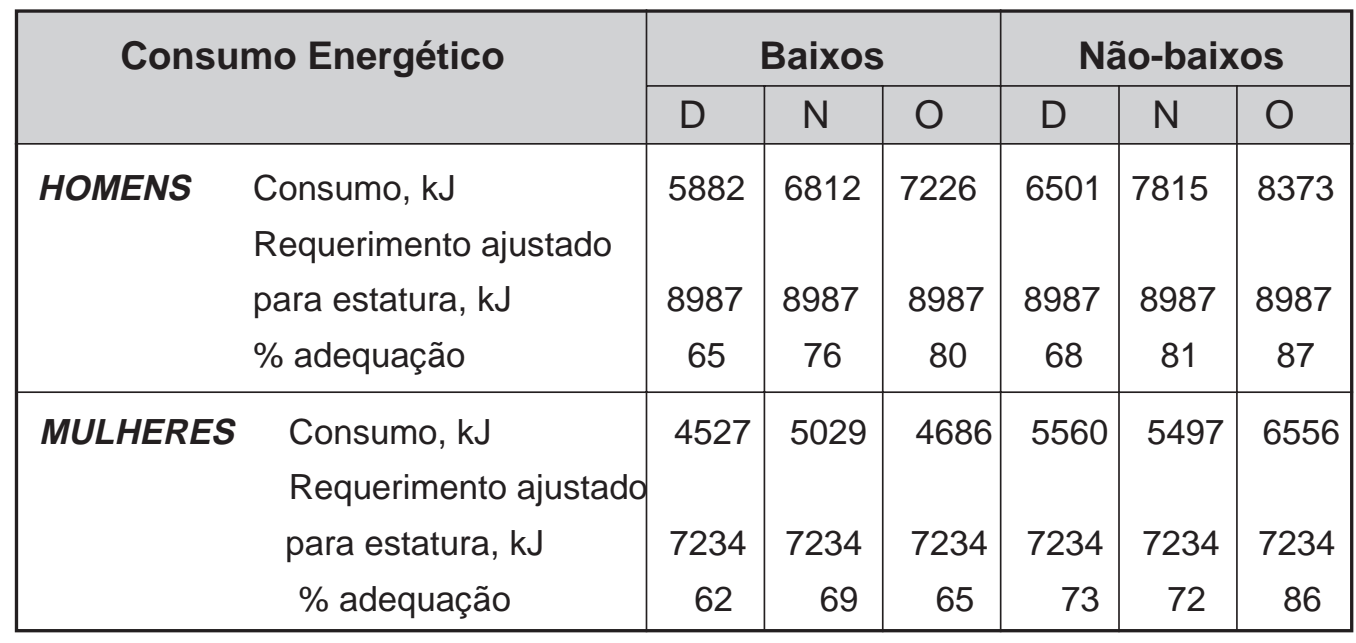

Fonte: Florêncio e cols., 2003.

$D=$ desnutridos $(I M C<20) ; N=$ normais $(I M C \geq 20<25) ; 0$ = sobrepeso + obesidade (IMC $\geq 25)$. 


\section{D esnutrição, diminuição do gasto energético e acúmulo de gordura corporal}

Para investigar essas questões, nosso grupo de pesquisa vem realizando uma série de estudos, transversais e longitudinais, com adolescentes de baixa estatura que moram em favelas, para averiguar se haveriam, de fato, alterações fisiológicas que favoreceriam a economia de energia (menor gasto energético) e maior acúmulo de gordura corporal nessa condição. Estas al terações explicariam o por quê de indivíduos com baixa estatura terem mais chance de se tornarem indivíduos obesos e doentes.

Em um estudo longitudinal de dois anos com meninas com baixa estatura, observamos uma maior susceptibilidade para engordar quando estas consumiam dietas mais ricas em gordura do que meninas normais, mesmo que a ingestão energética fosse insuficiente e abaixo do requerimento (Sawaya e cols., 1998).

Em um outro estudo transversal de três dias, examinamos a taxa de metabolismo de repouso (TM R), o gasto energético pós-prandial, o quociente respiratório $(Q R)$ e a oxidação de substrato. As crianças com baixa estatura tiveram TMR (por kg de peso corporal) menor e QR maior do que as crianças normais. A mbos os fatores levam à diminuição do gasto energético assim como à oxidação de gorduras, e predispõem fortemente para obesidade (H offman e cols. 2000a).

Em um outro grupo de experimentos, analisamos, ainda nas mesmas crianças, o gasto energético total (GET) durante sete dias, usando a técnica de água duplamente marcada (H offman e cols., 2000b). Encontramos que as meninas com baixa estatura possuíam GET menor, o que pode explicar o maior risco de se tornarem obesas como verificado em outros estudos (Sawaya e cols., 1995; Florêncio e cols., 2001).

Em um terceiro estudo (H offman e cols. 2000c), testamos a hipótese de que as crianças com baixa estatura possuem uma regulação da ingestão alimentar prejudicada. As crianças foram internadas durante três dias em uma unidade de pesquisa e possuíam disponibilidade de alimento à vontade. O fereceu-se um suplemento alimentar à base de iogurte (753 kJ) após o café da manhã e mediu-se 0 efeito deste na ingestão subseqüente durante 0 dia. 0 s resultados mostraram que não houve diferenças na ingestão alimentar entre as crianças normais e aquelas com baixa estatura, embora estas últimas pesassem $10 \%$ a menos que as outras. 0 consumo energético entre as crianças com baixa estatura e as normais, quando dividido por $\mathrm{kg}$ de peso corporal, foi maior nas últimas, assim como a razão consumo energético/ TM R. Além disso, as crianças com baixa estatura não diminuíram o consumo alimentar subseqüente ao suplemento, enquanto as crianças normais o fizeram, ou seja, as crianças desnutridas apresentaram "superalimentação" quando tiveram alimento à vontade.

Todos estes estudos reforçam a tese de que a desnutrição crônica ou baixa estatura altera a regulação dos mecanismos fisiológicos de conservação de energia e depósito de gordura, promovendo obesidade na vida adulta. 
A desnutrição, além disso, afeta outros mecanismos metabólicos, tais como o de controle da pressão arterial. R ealizamos estudos em adolescentes com baixa estatura para verificar a pressão arterial e encontramos uma preval ência muito alta de adolescentes desnutridos com hipertensão (13\%) em relação a adolescentes de mesma idade no Brasil (7\%) e no mundo (Task Force, 1996), (Fernandes e cols., 2003).

Em conclusão, os dados até agora relatados mostram a importância de se evitar a desnutrição desde o início da vida intra-uterina e a necessidade de cuidado com a qualidade da dieta em termos de consumo de proteínas de boa qualidade, minerais e vitaminas para se evitar o crescimento deficiente e a baixa estatura, pois esta última, como vimos, tem conseqüências deletérias que podem perdurar para o resto da vida.

Além disso, os resultados alertam para o fato de que programas de distribuição de alimentos (sem cuidados de saúde, avaliação do estado nutricional e cuidados com o tipo de alimentos ingeridos) podem agravar o quadro de obesidade e cardiopatias já crescente na população brasileira pobre que vive em zona urbana.

\section{Como fica o conceito de segurança alimentar e fome no Brasil?}

É preciso ter muito cuidado ao se utilizar os termos segurança alimentar e fome no Brasil. Estes termos têm sido utilizados por organismos internacionais como a FAO, cujo olhar se concentra em países do continente africano e sul da Ásia, onde os problemas da fome e da desnutrição são realmente muito graves. Só a I ndia possui mais de $50 \%$ das crianças desnutridas no mundo e nos países do sul do Saara tem aumentado significativamente o número de crianças que literalmente morrem de fome devido a guerras e a secas.

0 aumento na prevalência de obesidade em pessoas com baixa estatura descrito nas populações moradoras em favelas de São Paulo e M aceió é também encontrado nos Estados U nidos em populações de muito baixa renda que sofrem de insuficiência alimentar (não possuem alimento suficiente para o mês todo devido à baixa renda e sofrem literalmente, períodos de fome) ou in segurança alimentar, sobretudo mulheres e adolescentes (Casey e cols., 2001; Townsend e cols., 2001; Alaimo e cols., 2001 e Adams e cols., 2003). Estes estudos revelam que o conceito teórico, inferido pelos economistas, de que a insegurança alimentar leva necessariamente à fome ou à desnutrição não tem respaldo científico em países onde estas não atingem prevalências extremamente altas (acima de $20 \%$ da população infantil).

Aumentar ou incentivar o consumo de alimentos em adultos obesos, mesmo que estejam abaixo da linha de pobreza e vivam em condições de extrema miséria, não é absolutamente recomendável. N esse caso, só uma educação nutricional seria adequada, assim como o monitoramento das possíveis doenças associadas - hipertensão e diabetes - estas últimas crescendo velozmente na população brasileira (King e cols., 1998). É preciso identificar e tratar só os indivíduos realmente desnutridos nas comunidades pobres brasileiras; cuidar da quali- 
dade da dieta e monitorar a saúde dos adolescentes e adultos com baixa estatura. $N$ esse caso a distribuição de alimentos de acordo com a renda familiar, utilizando-se como nível de corte a linha de pobreza (abaixo de um dólar/ dia) é um desperdício de recursos e pode agravar a situação de saúde de muitos indivíduos. Por outro lado, um cuidado muito maior precisa ser dado ao pré-natal e às crianças desnutridas, mesmo aquelas com baixa estatura leve. Por isso, um governo interessado em aumentar a eficiência dos programas sociais, focalizar os mais necessitados e diminuir os custos destes, precisa ir ao encontro dos pobres no seu hábitat, realizar avaliações do estado nutricional e tratar caso a caso; além do acompanhamento cuidadoso das gestantes para evitar o baixo peso ao nascer. Este trabalho é exatamente aquele dos médicosque atendem a família na comunidade e dos agentes comunitários de saúde. É muito mais efetivo gastar recursos com eles.

\section{A partir dos conhecimentos atuais, qual seria o melhor programa para erradicação da desnutrição no Brasil?}

Seria um programa que contasse com ações integradas que valorizassem as iniciativas locais bem-sucedidas já existentes, respeitando culturas regionais, realizando a busca ativa doscasosna comunidadee, principalmente, aproveitando o patrimônio de cada pessoa, família e comunidade (Soares, 2002; www.desnutricao.org.br). A monitorização do crescimento de crianças pré-escolares precisa ser realizada diretamente na favela e comunidades pobres para se ter uma real avaliação do problema da desnutrição. Este é o grande limite de programas de Vigilância $\mathrm{N}$ utricional que se baseiam em levantamentos realizados exclusivamente nos Serviços de Saúde (e por isso muitas vezes encontram poucos desnutridos).

Só os médicos que atendem a família na comunidade e os agentes comunitários de saúde seriam suficientes para erradicar a desnutrição no Brasil? N ão, também seriam necessários programas para a melhoria das condições de saneamento básico e moradia, pois, como vimos, a baixa estatura está fortemente associada a estas condições.

As ações devem transcender os objetivos de visibilidade política a curto prazo e se dedicar a fortalecer e a utilizar os recursos e os atores sociais já existentes, mobilizando a formação de profissionais de saúde, escolas, programas de voluntariado e a atuação das organizações da sociedade civil. I sso dá a capilaridade necessária para a ação de diagnóstico e intervenção. Porém, para contar com a ação destes atores, é necessário investir na sua capacitação e na construção e implantação de instrumentos de supervisão e avaliação.

É importante quea formação dosprofissionais que atuam junto às comunidades pobres propicie o conhecimento aprofundado dos mecanismos de exclusão social, assim como dos mecanismos psicológicos associados à pobreza, como fatalismo, solidão, impotência, isolamento, debilidade(Solymos 2002; www.desnutricao.org.br). Em um artigo recente, Aguiar e Araújo (2002), descrevem que a renda mínima, 
para se tornar um poderoso instrumento de combate à pobreza e à desigualdade, deveria estar associada a outras políticas sociais. U ma família pobre que tenha uma renda mínima, mas que more em um bairro sem saneamento básico, tenha filhos sem acesso ao ensino fundamental, não tenha saúde adequada, não participe de forma pro-ativa na esfera política, e esteja submetida à arbitrariedade das ações policiais, continua em um processo de pobreza, desigualdade social, e mesmo exclusão.

Soares e Parente (2001) avaliaram os resultados do Programa Padegrin de reabilitação nutricional de Fortaleza. Sua estratégia de ação estava centrada na distribuição de alimentos, fornecendo para a criança desnutrida $4 \mathrm{~kg}$ de leite e uma lata de óleo e para as gestantes $2 \mathrm{~kg}$ de leite por mês. A captação dos beneficiários deu-se por demanda espontânea nos centros de saúde. A criança era avaliada mensalmente por uma equipe composta por nutricionistas, enfermeiros e fisioterapeutas. N este momento, a mãe tinha a oportunidade de receber orientação, individual ou em grupo, sobre saúde e nutrição. O s resultados mostraram que o percentual de crianças reabilitadas foi muito baixo e os autores apontam como motivos desse resultado a falta de envolvimento da (e na) comunidade, uma seleção questionável dos beneficiados e o não ter atingido a população mais pobre.

São necessárias, ainda, amplas ações educativas em nutrição e saúde junto à população em geral. E las podem ser realizadas nos ser viços de saúde e na comunidade ou como temas transversais de alunos do ensino fundamental e médio. É preciso se criar uma "cultura" de combate à desnutrição. Essas ações educativas devem levar em conta a realidade associada à pobreza (Sawaya, 2002; www.desnutricao.org.br).

A Tailândia é um caso exemplar da força da criação de uma cultura de combate à desnutrição. Este país conseguiu reduzir a prevalência de crianças com baixo peso de $50 \%$ em 1982 para 10\% em 1996, fruto do cumprimento de um compromisso político e um programa bem elaborado.

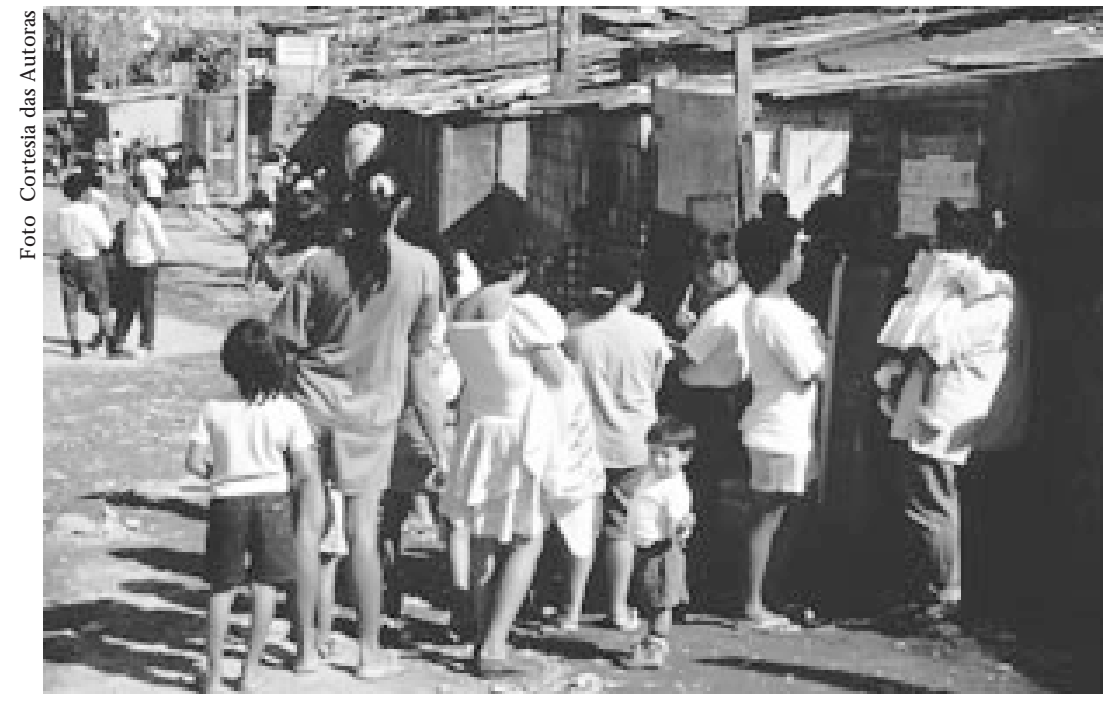

"M utirão de Pesagem": busca ativa de crianças desnutridasna comunidade 
Suas principais ações foram:

- Monitorização do crescimento de crianças pré-escolares diretamente na comunidade. $C$ rianças com grave déficit de crescimento receberam alimentação complementar.

- A educação nutricional foi incorporada nas políticas de saúde, nas escolas e na agricultura, em âmbito nacional, estadual, municipal e comunitário.

- O s custos foram minimizados a partir do re-treinamento dos funcionários públicos e da utilização de voluntários "mobilizadores" no âmbito da comunidade.

- O s financiamentos foram alocados para medidas seletivas de máximo impacto.

- Cada grupo de dez domicílios escolheu um voluntário adequado para se engajar em um programa nacional de treinamento e então monitorar mães e crianças na pró pria comunidade.

- U m programa de educação nutricional e comunicação encorajou o aleitamento materno e a introdução adequada e no tempo certo de alimentos complementares, além de medidas de higiene.

- Foi disseminada a informação sobre hábitos alimentares inadequados e tabus.

- A merenda escolar foi estabelecida em cinco mil escolas em áreas pobres.

- Segurança alimentar no domicílio e na comunidade foi reforçada por meio da promoção de hortas, árvores frutíferas, piscicultura e prevenção de doenças infecciosas em aves domésticas.

No gráfico abaixo, vê-se a projeção dessa experiência para nível mundial. Se experiências como essa ocorressem nos outros países em desenvolvimento, o número de crianças desnutridas se reduziria a apenas vinte milhões em 2020 (U N U , 2000).

Figura 4 - D éficit de políticas e prioridades impedirão o cumprimento da meta do Comitê de Alimentação M undial de 1990,

que era de reduzir a desnutrição pela metade até 0 ano de 2015

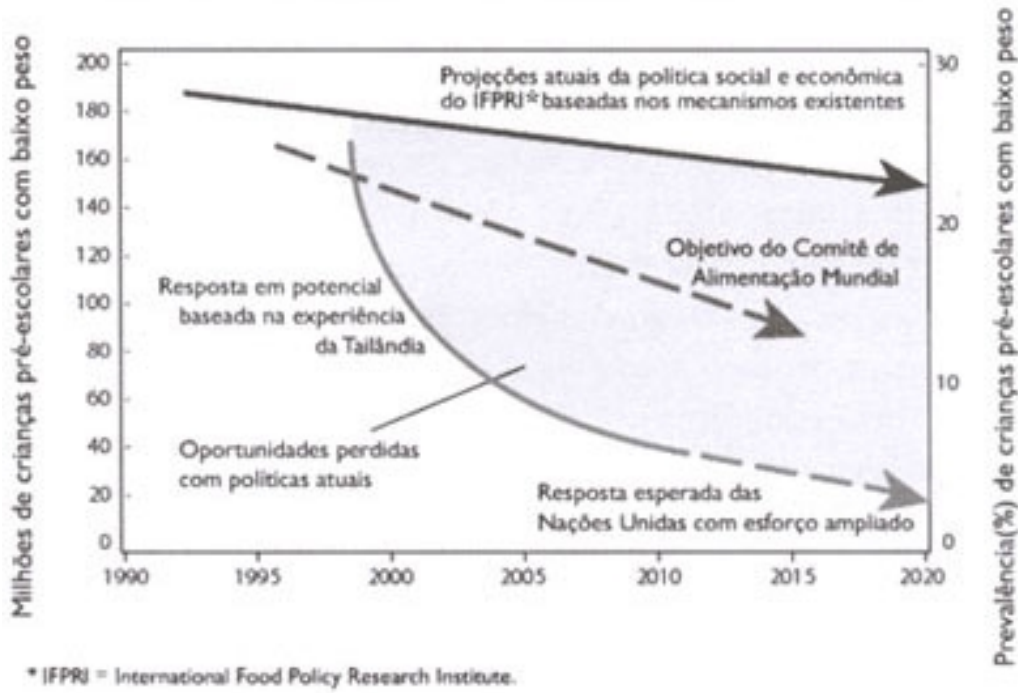




\section{Q ual seria a melhor estrutura?}

É fundamental que os programas de combate à desnutrição tenham uma atenção especial para a estrutura de atendimento. Por isso, seriam importantes tanto a criação de centros especializados como os $C$ en tros de R ecuperação eE ducação N utricional (Cren).

Esses C entros, embora tenham estrutura semelhante, não teriam os mesmos objetivos e critérios de tratamento daqueles da década de 19501960 (Solymos e cols. 1997). $\mathrm{N}$ aquela época, a intenção era de reduzir a mortalidade infantil por meio de uma recuperação rápida de peso em relação à estatura (ou seja, desnutrição aguda grave). O sCen-

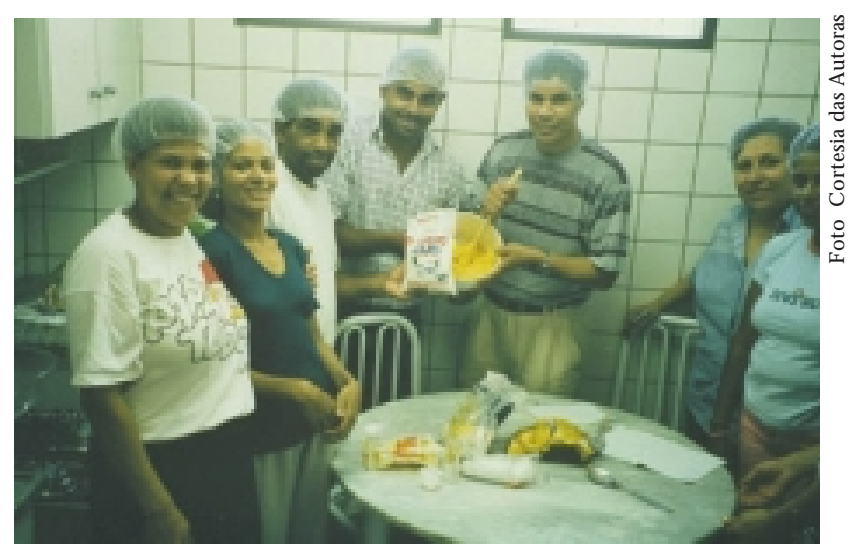

Pais de crianças desnutridas atendidas pelo $\mathrm{C}$ ren de São Paulo. trosatuais devem ter por objetivo a recuperação completa de peso e estatura pois, como visto, a baixa estatura aumenta o risco de doenças crônicas. 0 utra vantagem desses $C$ entros seria o fato de eles permitirem uma forma estável e eficiente de combate à miséria devido à penetração na comunidade e ao estabelecimento de "relações de confiança" (Soares 2002; www.desnutricao.org.br).

O sC entros deR ecuperação eEducação N utricional atuariam em três âmbitos:

- D ando suporte à atuação na comunidade através de atividades no campo social, psicológico, nutricional e de encaminhamento para outros serviços;

- Realizando atividade ambulatorial especializada para crianças desnutridas e

- Sendo hospital-dia para tratamento dos desnutridos mais graves.

Estes Centros de R ecuperação e Educação N utricional poderiam ter dois níveis de complexidade:

a) Constituindo-se como um Centro deR eferência no município para atendimento da população desnutrida nos três âmbitos (comunidade, ambulatório e hospital-dia), e para a geração de conhecimento e formação dos profissionais atuantes na área, além de centralização (elaboração e análise) de bancos de dados. Serão estes C entros de R eferência os responsáveis pela avaliação das intervenções realizadas e por cursos de formação para profissionais e líderes comunitários. Estes cursos po dem ser no local ou itinerantes. É importante que este Centros de R eferências tenham ligações com as universidades locais.

b) Atuando como Creche Especial ou $\mathrm{H}$ ospital-dia para crianças desnutridas (V ieira e cols., 1998), onde estas recebem cinco refeições diárias de muito boa qualidade e simultaneamente cuidados diários de saúde e combate às infecções associadas (Fernandes e cols., 2002; www. desnutricao.org.br). 
As famílias que possuem indivíduos desnutridos são aquelas de maior risco social e, por isso, é necessário acoplar às atividades desses Centros atividades de promoção humana para combater os mecanismos de exclusão social mais arrai-

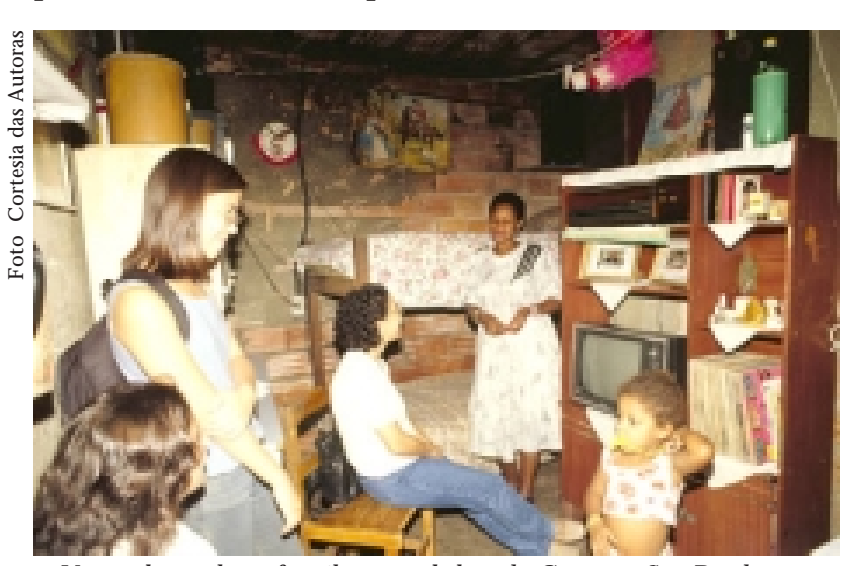

Visita domiciliar: família atendida pelo C ren em São Paulo.

gados em nossa sociedade, tais como, complementação de renda, cursos profisionalizantes etc. N a prática, estes C entros pontualizam as ações de identificação das famílias de maior risco social e centralizariam as ações de maior impacto com menor desperdício de recursos, evitando a multiplica ção e a sobreposição de ações. Eles permitem ações educativas e relacionamento direto e próximo dos profissionais com as famílias (Soares, 2002; www.desnutricao.org.br). Eles devem atuar também na formação educativa das crianças, considerando suas condições socioeconômicas, reforçando a rede familiar e o contato com outros serviços, rompendo o isolamento característico da miséria. É comum que as crianças mais pobres sofram preconceitos e exclusão na escola, por isso esses centros devem também ter contato direto com as instituições educacionais (Sawaya, 2002; www.desnutricao.org.br).

A intervenção deve se dar em diferentes níveis e áreas. Por isso, é necessário aplicar o conceito do trabalho interdisciplinar na própria constituição das políticas e das equipes de trabalho.

A seguir, colocamos um quadro que resume essa proposta para erradicação da desnutrição em nosso país.

\section{Bibliografia}

AD AM S, E. J.; GRU M M ER-ST RAWN , L. e CH AVEZ, G. "Food I nsecurity is Associated with I ncrease Risk of O besity in California Women". Journal of $\mathrm{N}$ utrition, vol. 133, 2003, pp. 1070-1074.

AGUIAR, M . eARAÚ J O , C. H . Bolsa-escola: educação para enfrentar a pobreza. U nesco, Brasília, 2002, p. 32.

ALAIM O, K.; OLSON, C. M. e FRONGILLO, E. A. "Low Family I ncome and Food Insufficiency in Relation to O verweight in US Children". A rchives of Pediatrics A dolescent Medicine, vol. 155, 2001, pp. 1161-1167.

BAN CO M UNDIAL. A valiação da pobreza no Brasil. Volumel : relatório principal. Divisão de O perações de Recursos H umanos, Região da América e do C aribe, Braślia, 1996.

. 0 combateà pobreza no Brasil: relatório sobre pobreza, com ênfase nas políticas voltadas para a redução da pobreza urbana. Volumel: relatório resumido. Brasília, 2001. p. 27. Disponível em: http:/ / www.obancomundial.org. 

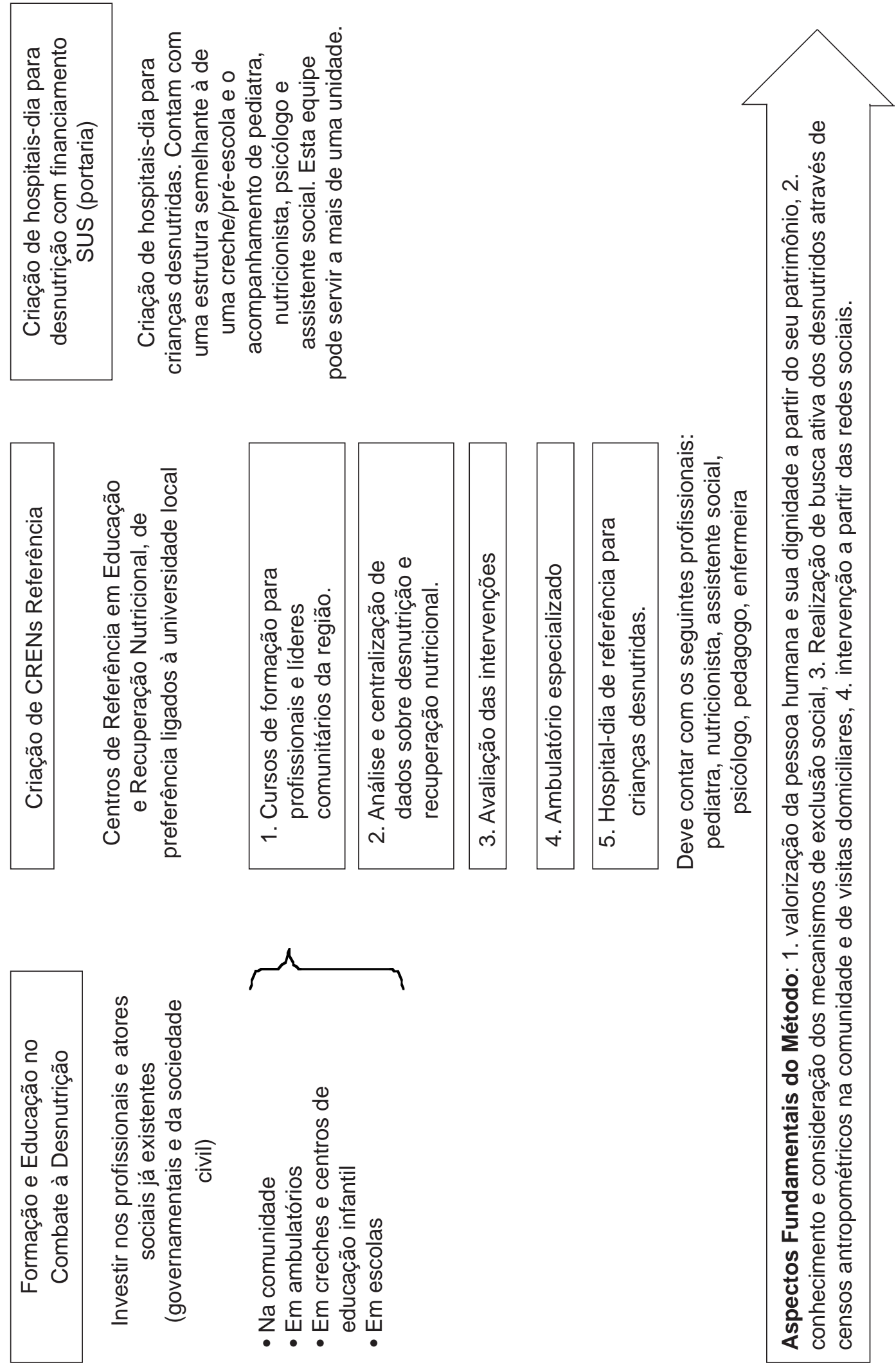
BARROS, R. P. e HENRIQUES, R. A. A estabilidadeinaceitável: desigualdadeepobreza no Brasil. Texto para discussão no 800. Rio de Janeiro, I pea, 2001. D isponível em: http:/ / www.ipea.gov.br.

BENFAM - Sociedade Civil Bem-Estar Familiar no Brasil. PNDS. Pesquisa nacional sobre demografia esaúde, 1996. Rio de Janeiro, Ed. Rio de J aneiro, 1997.

CASEY, P. H .; SZETO, K.; LENSING, S.; BOGLE, M. e WEBER, J. "Children in Food-I nsuficient Low-income Families". A rchives of Pediatrics A dolescent M edicine, vol. 155, pp. 508-514, 2001.

DOAK, C. M.; ADAIR, L. S.; MONTEIRO, C. e POPKIN, B. M. "O verweight and Underweight Coexist within Households in Brazil, China and Russia". Journal of N utrition, vol. 130, n. 12, 2000, pp. 2965-2971.

DUNCAN, B. B.; RUMEL, D.; ZELM ANOWICZ, A.; MENGUE, S. S.; DOS SAN TOS, S. e DALM AZ, A. "Social Inequality in M ortality in Sao Paulo State, Brazil". International Journal of Epidemiology, vol. 24, n. 2, 1995, pp. 359-365.

FAO - Food and Agriculture O rganization of the $U$ nited $N$ ations. Food I nsecurity; when People Live with $\mathrm{H}$ unger and Fear Star vation. Rome, 2001.

FERNANDES, B. S.; FERNANDES, M. T. B.; BISMARCK-NASR, E. M. e AL BU Q U ERQ U E, M. P. A bordagem clínica e preventiva, livro 3. SO LYM OS, G. M. B. e SAWAYA, A. L. (orgs.). Coleção Vencendo a D esnutrição. São Paulo, Salus Paulista, 2002. Disponível em: http:/ / www.desnutricao.org.

FER N AN DES, M. T.; SESSO, R.; M ARTIN S, P. A. eSAWAYA, A. L. "I ncreased Blood Pressure in Adolescents of Low Socioeconomic Status with Short Stature". Pediatric N ephrology, vol. 18, n. 5, 2003, pp . 435-439.

FERREIRA, H. S.; ALBU QUERQUE, M. F. M. e SILVA, R. “Perfil antropométrico da população residente em invasão do M ovimento dos Trabalhadores Rurais Sem Terra (M ST ). Porto Calvo, Alagoas-Brasil". R evista deE pidemi ologia, vol. 2, 1996, p. 114.

FLORENCIO, T. M.; FERREIRA, H. S.; D e FRAN ÇA, A. P.; CAVALCANTE, J. C. e SAWAYA, A. L. "O besity and $U$ ndernutrition in a Very-low-income Population in the City of M aceio, N ortheastern Brazil". British J ournal of N utrition, vol. 86, n. 2, 2001, pp. 277-285.

FLORÊNCIO, T. M.; FERREIRA, H. S.; CAVALCANTE, J. C.; LU CIANO, S. M. e SAWAYA, A. L. "Food Consumed does not Account for the $\mathrm{H}$ igher Prevalence of O besity among Short-statured Adults in a Very L ow Income Population in the N ortheast of Brazil (M aceió, Alagoas)". European J ournal of Clinical N utrition, 2003, no prelo.

GOMEZ, F.; GALVAN, R. R.; FRAN K, S.; CH AVEA, R. eVASQUEZ, J. "M ortality in Second and Third D egree M alnutrition". J ournal of Tropical Pediatrics, vol. 2, 1956, pp. 77-83.

GUIM ARÃES, L. V.; LATORRE, M. do R. eBARROS, M. B. A. "Fatores de risco para a ocorrência de déficit estatural em pré-escolares". CadernosdeSaúdePública, vol. 15, 1999, pp. 605-615.

H OFFM AN, D. J .; SAWAYA, A. L,; VERRESCHI, I ; TU CKER, K. eROBERTS, S. B. "Why are Nutritionally Stunted Children at Increased Risk of O besity? Studies of metabolic Rate and Fat Oxidation in Shantytown Children from São Paulo, Brazil". A merican J ournal of Clinical N utrition, vol. 72, 2000a, pp. 702-707.

HOFFMAN, D. J.; SAWAYA, A. L.; COWARD, A.; WRIGH T, A.; M ARTINS, P. A.; N ASCIM ENTO, C.; TU CKER, K. eROBERTS, S. B. “E nergy Expenditure of Stunted 
and Nonstunted Boys and Girls Living in the Shantytowns of São Paulo, Brazil". A merican J ournal of Clinical N utrition, vol. 72, 2000b, pp. 1025-1031.

HOFFMAN, D. J.; ROBERTS, S. B.; VERRESCHI, I.; MARTINS, P. A.; NASCIMENTO, C.; TU CKER, K. e SAWAYA, A. L. "Regulation of E nergy I ntake M ay Be I mpaired in N utritionally Stunted Children from the Shantytowns of São Paulo, Brazil". J ournal of Nutrition, vol. 130, 2000c, pp. 2265-2270.

KAC, G. "Tendência secular em estatura: uma revisão da literatura". C adernos deSaúde Publica, vol. 15, 1999, pp. 451-461.

KING, H .; AU BERT, R. E. e HERM AN, W. H . "Global Burden of Diabetes, 19952025". Diabetes Care, vol. 21, 1998, pp. 1414-1431.

KUH , D.; H ARDY, R.; CH ATURVEDI, N . e WAD SWORTH , M. E. "Birth Weight, Childhood Growth and Abdominal O besity in Adult Life". I nternational J ournal of $O$ besity and $R$ elated $M$ etabolic $D$ isorders, vol. 26, n. 1, 2002, pp. 40-47.

LAW, C. M.; BARKER, D. J. P.; OSM OND, C.; FALL, C. H. e SIM MONDS, S. J. "Early Growth and Abdominal Fatness in Adult Life". Epidemiology in Community. H ealth., vol. 46, 1992, pp. 184-186.

LOOS, R. J.; BEUNEN, G.; FAGARD, R.; DEROM, C. e VLIETINCK, R. "Birth Weight and Body Composition in Young Women: A Prospective T win Study". A merican J ournal of Clinical N utrition, vol. 75, n. 4, 2002, pp. 676-682.

MARQUES, E.; TORRES, H. e SARAIVA, C. "Favelas no M unicípio de São Paulo: estimativas de população para os anos de 1991, 1996 e 2000". Base Cartográfica Digital das Favelas do M unicípio de São Paulo. Centro de Estudos da M etrópole/ Prefeitura M unicipal de São Paulo, 2003.

NEPP/ U NICAM P. Estratégias para combater a pobreza no Brasil: programas, instituições e recursos. R elatório Final. Campinas, 1994.

OPAS - ORGANIZACIÓN PAN AM ERICANA DE LA SALUD. La Salud en las Américas. Washington, D.C., vol. 1, 1998, 368p. (Publicación Científica, n. 569).

RAVELLI, G. P.; STEIN, Z. e SU SSER, M. "O besity in Young M ean After Famine Exposure in U tero and Early Infancy". N ew England M edical J ournal, vol. 259, 1976, pp. 349-53.

ROSEBOOM, T. J.; VAN DER MEULEN, J. H.; RAVELLI, A. C.; VAN MONTFRANS, G. A.; OSMOND, C.; BARKER, D. J e BLEKER, O. P. "Blood Pressure in Adults after Prenatal Exposure to Famine". J ournal of $\mathrm{H}$ ypertension, vol. 17, n. 3, 1999, pp. 325-330.

SAWAYA, A. L.; DALLAL, G.; SOLYMOS, G. M.; SOUZA, M. H .; VENTURA, M. L.; RO BERTS, S. B. eSI GU LEM , D. M. "O besity and M alnutrition in a Shantytown Population in the City of São Paulo, Brazil". O besity R esearch, vol. 3, suppl. 2, 1995, pp. 107-115.

SAWAYA, A. L. "Transição: desnutrição energético-protéica e obesidade". Em (org.). D esnutrição urbana no Brasil em um período de transição. São Paulo, Cortez, 1997.

SAWAYA, A. L.; GRILLO, L. P.; VERRESCH I, I.; SILVA, A. C. e ROBERTS, S. B. " $M$ ild Stunting is Associated with $\mathrm{H}$ igher Susceptibility to the Effects of $\mathrm{H}$ igh Fat D iets: Studies in a Shantytown Population in São Paulo, Brazil". J ournal of N utrition, vol. 128, 1998, pp. 415-420.

SAWAYA, S. M . A bordagem pedagógica, livro 5. SO L YM OS, G. M . B. e SAWAYA, A. L. 
(orgs.). Coleção Vencendo a D esnutrição. São Paulo, Salus Paulista, 2002. D isponível em: http:/ / www.desnutricao.org.

SAWAYA, A. L.; MARTINS, P. A.; HOFFM AN, D. J. e ROBERTS, S. B. “The Link between Childhood U ndernutrition and Apparent Risk of Chronic D iseases in Adult Life: A Case Study of Brazil". N utrition R eviews, 2003, no prelo.

SEH AB - São Paulo. Favelasna cidade de São Paulo. São Paulo, 1994.

SICHIERI, R.; SIQU EIRA, K. S.; PEREIRA, R. A. e ASCHERIO, A. "Short Stature and $\mathrm{H}$ ypertension in the $\mathrm{C}$ ity of Rio de Janeiro, Brazil". Public $\mathrm{H}$ ealth $\mathrm{N}$ utrition, vol. 3, n. 1, 2000, pp. 77-82.

SO ARES, M. L. P. V. A bordagem social, livro 4. SO LYM OS, G. M. B. e SAWAYA, A. L. (orgs. ). Coleção Vencendo a D esnutrição. São Paulo, Salus Paulista, 2002. Disponível em: http:/ / www.desnutricao.org.

SO ARES, N. T. ePARENTE, W. G. "D esnutrição e resultados de reabilitação em Fortaleza". R evista de N utrição, Campinas, vol. 14, n. 2, 2001, pp. 103-110.

SOLYMOS, G. M. B.; SAWAYA, A. L.; FERRARI, A. A.; VIEIRA, M. de F. A. e UNEGBU , C. H. "Centro de Recuperação e Educação Nutricional: uma proposta para o combate à denutrição energético-protéica". Em SAWAYA, A. L. (org) D esnutrição urbana no Brasil em um período de transi ção. São Paulo, Cortez, 1997, p. 191.

SO L YM OS, G. M . B. A bordagem psi cológica, livro 6. SO L YM OS, G. M. B. e SAWAYA, A. L. (orgs.). Coleção Vencendo a D esnutrição. São Paulo, Salus Paulista, 2002. D isponível em: http:/ / www.desnutricao.org.

SZWARCWALD, C. L.; ANDRADE, C. L. T. e BASTOS, F. I. "Income Inequality, Residential Poverty Clustering and I nfant M ortality: A Study in Rio deJ aneiro, Brazil". Social Science \& Medicine, vol. 55, 2002, pp. 2083-2092.

UNU - U nited Nations U niversity. "Ending M alnutrition by 2020: An Agenda for Change in the M illennium". Food and N utrition Bulletin, vol. 21, n. 3, 2000.

VIERA, M. de F. A; SOLYMOS, G. M. B.; SOUZA, M. H. do N .; FERRARI, A. A; U NEG BU , C. eSAWAYA, A. L. R evista da A ssociação M édica Brasileira, vol. 44, n. 4, 1998, pp. 294-300.

WATERLO W, J. C. "Classification and D efinition of Protein-energy M alnutrition". Em BEATON , G. H .; BEN GO A, J. M . (orgs.) N utrition in PreventiveM edicine: TheM ajor D eficiency Sydromes, Epidemiology, and A pproaches to Control. Geneva, WH O, 1976, pp. 530-555.

Www. desnutricao.org - Portal vencen do a denutri ção. SAWAYA, A. L. e SO LYM OS, G. M. B. (orgs.).

R ESUMO - ESTE ARTIGO procura mostrar alguns dados sobre as condições nutricionais e de pobreza de duas populações moradoras em favelas, nos municípios de M aceió e São Paulo. O s resultados apresentados revelam que no Brasil atual, a associação entre pobreza e estado nutricional (incluindo desnutrição energético-proteíca e obesidade) é complexa e ainda pouco conhecida. H á um número elevado de indíviduos obesos nas populações brasileiras que vivem abaixo da linha de pobreza nas zonas urbanas. A obesidade co-existe com altas prevalências de desnutrição. Esses achados estão associados com alimentação deficiente, so bretudo em qualidade, levando à alta prevalência de baixa estatura. Vários estudos mostram que a obesidade encontrada na população pobre pode ser 
sequela de desnutrição precoce e apontam para a necessidade de programas que: sejam focalizados nos indivíduos realmente desnutridos e consequentemente realizem avaliação do estado nutricional, cuidados de saúde caso a caso, forte atenção ao pré-natal, melhorem as condições de moradia e combatam o analfabetismo materno. 0 artigo recomenda ainda a criação de Centros de Educação e Recuperação Nutricional para combater a desnutrição, visando recuperação da baixa estatura, com forte enfoque de intervenção na comunidade.

A bstract - THIS ARTICLE shows the socioeconomic and nutritional conditions of two shantytown populations from the city of São Paulo and M aceió. The results reveal that in Brazil, the association between poverty and nutritional status (including undernutrition and obesity) is complex and not well known. There is a large number of obese individuals among people living below the poverty line in urban areas. O besity co-exists with undernutrition and food insecurity, specially in stunted individuals. A series of studies have shown that obesity can be a sequelae of previous undernutrition. The article describes the need for programmes that focus only the real undernurished individuals and consequently, measure nutritional status, promote health and prenatal care, improve living conditions and fight against mother illiteracy. From the results presented, the article recommend the setting up of Centers for Nutritional Rehabilitation, to fight against undernutrition, aiming the recovery of stunting, and with a strong community based intervention.

A na L ydia Sawaya é formada pelo Instituto de Biociências da U SP e professora adjunta livre docente do D epartamento de Fisiologia da U nifesp (U niversidade Federal de São Paulo), exercendo atualmente o cargo de chefia deste. É coordenadora do Grupo de Estudos em N utrição e Pobreza do IEA-U SP e presidente do Centro de Recuperação e Educação N utricional.

Gisela M aria BernardesSolymoséformada pelo Instituto de Psicologia daU SP eatualmente é professora-visitante doutora da U nifesp, além de diretora de Projetos do Centro de Recuperação e Educação N utricional.

Telma Maria Toledo Florêncio é formada pela U niversidade Federal de Pernambuco e professora do curso de N utrição da U niversidade F ederal do Alagoas.

Paula A ndrea Martinsé formada pela Faculdade de Saúde Pública da U SP e aluna de doutorado da U nifesp.

Texto recebido e aceito para publicação em 28 de maio de 2003. 
